\title{
The Role of Inner Speech Instruction in Fostering Visual and Auditory Learners' Reading Ability and Perception
}

\author{
Karim Shabani \\ Ghazaleh Khasrei \\ Iman Bakhoda
}

\author{
English Language Department \\ Allameh Mohaddes Nouri University \\ Iran
}

Email:shabanikarim@gmail.com,gkhasree@yahoo.com

\begin{abstract}
The purpose of this study was to investigate whether inner speech instruction had any significant effect on upper-intermediate EFL learners' reading comprehension. To this end, 60 female subjects participated in this study and were assigned to the experimental and control groups each consisting of 30 participants. The same teaching materials comprising twelve reading texts were taught to both groups through a 10-session treatment with a difference in the procedure during which the experimental group underwent an inner speech instruction while the control group did not receive such an instruction. Results of paired samples t-test indicated the effectiveness of inner speech instruction in the experimental group. Moreover, the interview analysis revealed that the visual and auditory learners preferred to visualize and hear voices while completing the task and developing a positive perception towards the use of inner speech as a tool to enhance their reading ability. It is assumed that applying inner mental self-speech instruction in a social context of classroom leads learners to move from inter-psychological to intrapsychological functioning in order to modify their current developed ability to higher cognitive performance.
\end{abstract}

Keywords: Inner speech instruction, visual style, auditory style, reading comprehension.

\section{INTRODUCTION}

Dealing with comprehension difficulties is a crucial aspect in EFL/ESL pedagogical contexts which requires both cognitive and metacognitive processes. One of the most controversial cognitive processes in second language acquisition is inner speech. Based on Vygotsky's socio-cultural theory (1986), inner speech has different definitions, such as "inner dialogue" (p. 243), "speech almost without words" (p. 244) and "thought connected with words" (p. 249). On the other hand, private speech is a different mode of inner speech that occurs at the level of processing in which thought changes into external speech. One of the skills that beg for the use of inner speech during comprehension is reading. 
Following the concept of inner speech in socio-cultural theory, Sokolov (1972, cited in Guerrero, 2005) emphasized its importance in the processing of FL speech or text during listening or reading. In this regard, students could comprehend and remember a foreign language text effectively when their reading or listening is accompanied by inner speech in search for the key words or semantic sentences. Sokolov argued that the process of understanding a text by repeating phrases and making an idea requires the articulation of words in an unfold manner, and conversely, the simpler the text, the production would be more abbreviated (p. 182). There are many researches that investigated the role of private speech for problem solving and controlling behaviours (Winsler, Diaz \& Montero, 1997; Winsler et al. 2007), the use of private speech forms and function in different contexts (Buckwalter, 2001; Dicamila \& Anton, 2004; Platt \& Brooks, 1994; Saville-Troike, 1988; Vilamill \& De Guerrero, 1996) and inner speech during task completion (Sokolov, 1972, cited in Guerrero, 2005) arguing that advanced FL learners experience immediate text comprehension without translation and are able to comprehend fully with their eyes and say the words inwardly. A study by Upton and Lee-Thompson (2001) made connections between inner speech and L2 learning in the context of reading. They indicated that reading a passage while simultaneously verbalizing thoughts for processing L2 texts could cause to mentally translate passages into L1 in order to help them about structures, content and meaning of L2 texts.

Meanwhile, there is empirical support in a large number of studies indicating that task type, proficiency level, and learner styles may differently affect the nature of performance and planning (Guerrero, 2005). According to Keefe and Ferrell (1990), learning style is a complex characteristic in which the whole is greater than the parts, and it is a combination of internal and external operation that reflects behaviour. In EFL contexts, students are different in acquiring a language with respect to their learning styles. Among a plethora of style categories, two types of audio and visual learning styles are the subject of investigation in this study. Based on Oxford (1995, p. 36), visual learners are learners who prefer to learn via the visual channel. Therefore they like to read a lot, which requires concentration and time to be spent alone. Visual students need the visual stimulation of bulletin boards, videos and movies. They must have written directions if they are to function well in the classroom. But auditory learners are students who enjoy the oral-aural learning channel. Thus, they want to engage in discussions, conversations, and group work. These students typically require only oral directions.

Having a glance at learners' inner speech and its role in second language reading comprehension reveals that inner speech has not received enough attention in the field of EFL/ESL teaching. Thus, there is a need to develop inner speech in EFL reading courses for helping them to overcome comprehension difficulties during text reading. To get this, the present study is an attempt to investigate the effect of inner speech instruction on auditory and visual learning styles' reading comprehension ability. It also sought to determine the difference between both styles' mastery of L2 comprehension, in-depth nature of inner speech and their perceptions towards inner speech instruction. 


\section{REVIEW OF THE RELATED LITERATURE}

\section{Overt and covert inner speech}

Inner speech as a vital aspect of second language learning has occupied a great body of research for the past few decades. Language learning research revealed the effect of inner speech on EFL/ESL learners' performance among the listening, speaking, reading and writing. With regard to the definition of inner speech from Oxford Dictionary, it is "The silent expression of conscious thought to oneself in a coherent linguistic form". There is an increasing body of research illustrating the role of inner speech in educational psychology. Some scholars in this area defined inner speech as the "silent speech for oneself" (Frawley, 1997, p. 95). According to Vygotsky (1986, p. 235 and 243), inner speech is as a completely separate speech function, a "mental draft" and "inner Dialogue". Sokolov (1972) defined it as a soundless, mental speech, that emerges quickly when we think about something, plan or solve problems in our mind, recall conversations or books read that were heard, read and written silently (Cited in Guerrero, 2005).

There are different functions of inner speech that second language learners use when undertaking different skills. L1 inner speech functions as a thorough regulator for L2 learners. Guerrero (2005) explains that "the vast range of higher mental functions-logical memory, mediated perception, voluntary attention, reasoning, remembering, planning, self-reflection, problem-solving-normally mediated by the LI can also be mediated by an L2" (p. 177).

Some researchers studied inner speech function use in second language learners during completing cognitively demanding tasks. For instance, Guerrero $(1994,1999)$ concluded that the rehearsal function of inner speech is the key role in the internalization of the second language social speech and L2 inner speech. In another empirical study, Guerrero (2005) investigated the early stages of inner speech development and tested the effectiveness of L2 inner speech among 16 beginning ESL college students. She found that there are four main types of L2 inner speech 1) concurrent processing of read or heard language, 2) recall of language heard, read or used previously, 3) preparation before writing or speaking and 4) silent verbalization of thoughts. Lantolf (1997) examined the Din wherein 156 college students were taking Spanish classes as their FL and concluded that functions of language play decrease with proficiency; in other words second language students sometimes engage in covert speech (Cited in Guerrero, 2005).

With respect to the overt inner speech, some researchers defined it as the observable physiological manifestations of covert verbal behaviour and it is the audible speech that reveals itself during performing a challenging task (Guerrero, 2005). Some of the scholars investigated second language learners' private speech use in L2 pedagogical contexts. Among many researchers who have worked on the private speech, Frawely and Lantolf (1985) were two researchers that were inspired by Vygotsky's ideas, and did some researches on the role of mediation in L2 private speech. McCafferty (1992) investigated the influence of cultural background on selfregulatory function of private speech based on a narrative story from thirty university students in Mexico, with two 15 groups of Hispanic and Asian backgrounds. He 
concluded that the other-regulatory functions were different in individuals with regard to their progressive aspects. Another study by Tahmasebi and Yamini (2011) focuses on private speech and scaffolding in reading comprehension among 54 EFL learners from experimental and control group, wherein the experimental group benefited from private speech and artefacts for paraphrasing the texts but the control group had not such an instruction. The results showed that the two groups did not perform significantly in the final exam, but in terms of oral paraphrase, the experimental group outperformed the control group. Khorshidi and Abadikhah (2013) reported that Iranian EFL students at different levels of language proficiency reported the loud and whisper forms were used more than abbreviated forms and in the content area the question/answer and repetition were more dominant.

Thus recent research has increasingly been geared toward effective mediating factors of inner speech. Instructional mediation plays a significant role in enhancing internalization of the L2 and causes inner speech development, and without social exposure and participation in external activities in second language there is nothing to internalize and no social help for mediational activities at the interpersonal level (Guerrero, 2005). Vygotsky's (1986) idea is that the development of inner speech relied on the outside factors. Based on Tomlinson (2000, 2001, cited in Guerrero, 2005) there are some inwardly activities that cause fostering internalization and externalization of second language.

\section{Learning Styles}

According to Reid (1995), "learning styles are internal-based characteristics of individuals for the intake or understanding of new information" (cited in Barzegar and Tajalli, 2013). Keefe (1979) defines learning style as the amalgamation of cognitive, affective, and physiological factors that serve as relatively stable indicators of how a learner perceives, interact with, and responds to the learning context.

Personality factors are one of the main topics in psychology that deeply describe individual differences in a learning context (Aliakbari \& Abol-Nejadian 2013; McChlery, \& Visser, 2009; Sadler-Smith, 2010; Williams, Brown, \& Etherington, 2012). According to Putintseva (2006), there are four scales of style preferences of Myers-Briggs. In this style scale, people are classified according to their preferences for being introverted, that prefer to flow mainly to the inner world of concepts and ideas and in contrast the extroverted people like the outer world for actions. Sensing people prefer to perceive immediate, real, practical facts of experience and life, but on the other hand intuitive people choose to perceive possibilities, relationships, and meanings of experiences in life. Thinking and feeling people tend to make judgments or decisions objectively and impersonally; and subjectively and personally, respectively. Judging styles like to act in planned and decisive way and perceiving styles prefer to act in spontaneous and flexible way.

According to Claxton and Murrell (1987), Witkin's work on cognitive style in the last 50 years is the most extensive and detailed research that focused on the field dependence-independence dimension of cognitive style. According to him, people who are profoundly affected by the surrounding field are called "field dependent", those who are not influenced by the surrounding field are called "field independent". From 
social interaction point of view, it is possible to say that these two personality models differ considerably. In other words, surrounding environment will affect these two models' perceptions. On the other hand, from biological point of view, genetic factors are very important. Field-independent persons were encouraged at an early age to be autonomous, but field-dependents are more strongly influenced by authority figures and peer groups. Based on Dorneyei (2005), field-dependents are more responsive in interacting with the environment, and thus, have a stronger interpersonal orientation and better alertness to social cues than field-independents (p. 137).

A further variable worth talking about in the area of learning styles is the sensory style preferences. This dimension concerns the perceptual modes through which students get information, which are classified into visual, auditory, kinesthetic and tactile learners.

Visual: these learners learn well from visual channels, chunks of information like lectures, handouts and different visual aids (Dorneyei, 2005). They need to read and obtain information from their visual stimulation. In other words, they prefer to learn via conversations and oral directions without any visual backup to be confused (Oxford 2003).

Auditory: These types of learners learn best through auditory input such as lectures or audiotapes, and they prefer discussions and group work. They prefer oral practice without books (Dorneyei, 2005). This style is in contrast with visual style in that they enjoy role-plays and similar activities (Oxford 2003).

Kinaesthetic and tactile: According to Dorneyei (2005), kinaesthetic and tactile learners are often grouped together named "haptic" style category because they are somehow related to each other but are not identical. The kinaesthetic learners tend to learn through complete body experience, whereas tactile learners prefer touching ways for learning. According to Oxford (2003), kinaesthetic learners like more movements and benefit more from working with tangible objects and flashcards.

\section{RESEARCH QUESTIONS}

This study attempts to respond to the following research questions:

1. Does inner speech instruction have significant effects on L2 learners' reading comprehension?

2. Does inner speech instruction lead to significant differences between visual and auditory learners in reading comprehension tasks?

3. Does inner speech instruction lead to significant changes in visual learners in reading comprehension tasks?

4. Does inner speech instruction lead to significant changes in auditory learners in reading comprehension tasks?

5. What is the nature of inner speech in auditory and visual style learners and their perceptions toward inner speech? 


\section{METHODOLOGY}

\section{Study Design}

This study followed experimental-control group paradigm as the main design. Best's (2006) non-probability sample design was employed to select 60 EFL learners. To instruct second language inner speech in experimental group, we applied Guerrero's (2005) inner speech strategies. In this regard, the learners in experimental group were encouraged to deploy inner speech during reading comprehension passages (more information presented in the following sections). The following table represents the overall design of the study:

Table 1: Overall Study Design

\begin{tabular}{|c|c|c|}
\hline Procedure & Experimental group & Control group \\
\hline $\begin{array}{l}\text { Placement } \\
\text { test }\end{array}$ & 30 learners & 30 learners \\
\hline Pre-test & $\begin{array}{l}\text { VAK learning style questionnaire, } \\
\text { and reading comprehension test }\end{array}$ & $\begin{array}{l}\text { Reading comprehension } \\
\text { test }\end{array}$ \\
\hline Treatment & Inner speech instruction condition & Traditional method \\
\hline Post-test & Reading comprehension test & $\begin{array}{l}\text { Reading comprehension } \\
\text { test }\end{array}$ \\
\hline Interview & Six participants & - \\
\hline
\end{tabular}

\section{Participants}

The participants in this study were female students studying English as a foreign language at Baran English institute in Mashhad, Iran. They spoke Farsi as their first language. The range of their age was between 20-30 years. At the outset of the study, Oxford Placement Test was administered to 81 students. Best's (2006) non-probability sample design was employed to select 60 learners (the ones ranging between one standard deviation above and one below the mean classified as the upper-intermediate level of English Proficiency), which were randomly assigned to the experimental and control groups.

\section{Instrumentation}

\section{Oxford Placement Test}

Oxford Placement Test was used to assess learners' level of English proficiency. This test includes 60 multiple choice questions on grammar and vocabulary with interpretation sheet. The students were asked to answer the questionnaire in 30 minutes. The aim of using this test is to ascertain that all of the students are at upperintermediate level and homogenous. KR 21 demonstrated a reliability of 0.81 for the test. 


\section{Learning Style Questionnaire}

In order to learn about the participants' learning styles, an adapted (translated) version of VAK (visual, auditory, and kinaesthetic) learning style questionnaire (Chislet \& Chapman, 2005; cited in Abdollahi \& Tahriri 2012) was used. The validity and reliability of this questionnaire was ensured. The validity of the questionnaire was established through receiving feedback from 5 experts concerning the content clarity, relevance and adequacy of the questionnaire. Test re-test method was employed to determine the reliability of the questionnaire. Pearson Correlation Coefficients demonstrated a reliability of 0.83 for visual learning style, 0.79 for auditory learning style, and 0.86 for Kinaesthetic learning style.

The participants were asked to complete 30 statements in this survey. They were marked as visual or auditory language learners based on their answers. It is worth mentioning that the kinaesthetic section of the VAK questionnaire was omitted because it was irrelevant to the present study as it was not considered as a variable. The following table encapsulates learners learning styles preferences:

Table 2: Classification of Participants into Auditory and Visual Learners

\begin{tabular}{cllll}
\hline Learning styles & Frequency & Percent & $\begin{array}{l}\text { Valid } \\
\text { Percent }\end{array}$ & $\begin{array}{l}\text { Cumulative } \\
\text { Percent }\end{array}$ \\
\hline auditory & 18 & 60.0 & 60.0 & 60.0 \\
\hline visual & 12 & 40.0 & 40.0 & 100.0 \\
\hline Total & 30 & 100.0 & 100.0 & \\
\hline
\end{tabular}

The results of descriptive statistics showed that $60 \%$ and $40 \%$ of the participants from the experimental group preferred to be auditory and visual respectively.

\section{TOEFL Reading Comprehension Test}

For the pre-test and post-test, TOEFL IBT Reading Comprehension Test was used to assess and compare both control group and experimental group's performance. This test was based on B2 (upper-intermediate) language proficiency level and served as both pre-test and post-test. The test contained four passages with twenty-three four choice questions and seven fill-in-the-blank items. The reliability of the test was 0.72 computed through the KR-21 formula in the piloting phase of study with 10 students of upper-intermediate level.

\section{Interview}

The interview questions were based on three materials namely open-ended questionnaire, diary questions, and structured interview questions by De Guerrero that were mixed up with the researcher's rationale for the aim of the research and it consisted of five questions (Guerrero, 2005; Lantolf, 1994). In order to increase the validity of structured interview, one-on-one interview was conducted in the study. However, the learners' performances were assessed by three experts. The inter-rater reliability demonstrates coefficient of 0.763 . 


\section{DATA COLLECTION PROCEDURE}

In the first phase of data collection procedure, the researcher's aim was to find a sample size of 60 homogenous students at the upper-intermediate level of language proficiency; therefore, the Oxford Placement Test was administered to 81 female EFL learners and thereby selecting the 60 learners were randomly assigned into one experimental and one control group with 30 participants in each group. Secondly, the VAK learning style questionnaire, and reading comprehension test as a pre-test were used among participants in the experimental group, but the control group just had reading comprehension test as a pre-test.

After finishing the aforementioned steps, the participants in the experimental group went through inner speech instruction condition. The students were supposed to have the reading class two times a week and each session was about 90 minutes. This course aimed to enhance students' reading comprehension in English through inner speech encouragement and instruction during the reading tasks. In other words, they had inner speech instruction while simultaneously working on twelve reading texts from "select reading" (upper intermediate level). The aim of instruction was to build a door in order to enter the students' mind. The instruction on inner speech could be summarized as follows:

As the book had some before-reading activities, the students were asked to undertake them. The following procedure describes the teacher's activities in the class during the reading procedures:

1. The teacher wrote the topic on the board and addressed the students by saying "talk to yourself about the topic and give me your ideas about it".

2. The teacher read aloud the text and asked the students to repeat the words that they had difficulty to pronounce and it was done silently.

3. Next, students were asked to silently read each paragraph and had inner speech during reading in order to find the main idea of each paragraph, to paraphrase the content, and to give the summary of each reading. It is worth noting that the students were supposed to do the paraphrasing collaboratively and then share their ideas with the class.

4. At the end of each reading, the teacher briefly talked about the gist of readings.

5. It is worth mentioning that the teacher also familiarized the students with different functions of inner speech and encouraged them to use the functions.

6. After that students were asked to do the after-reading exercises.

The participants in the control group studied the same reading texts with exactly the same time duration and number of sessions except the method of instruction which was designed according to the traditional method of teaching. The teacher read the text and asked the students to give the main idea and paraphrase it for giving the summary.

Post-test: After finishing the treatment sessions, the students in both groups were asked to answer the same reading comprehension test. Six participants (3 Visual and 3 Auditory) from experimental group were asked to take part in an interview session. 


\section{DATA ANALYSIS}

The collected data were analysed both quantitatively and qualitatively. At the quantitative level, independent sample t-test was employed to statistically reveal whether there was a proficiency difference between the two groups' (control and experimental) pre-test performance. The learners' homogeneity was assessed through the use of Levene's test. Also, two groups' post-test differences were unravelled by the independent sample t-test. Besides, paired t-test was employed to assess the experimental group's performance on the pre-test and post-test. Cohen's effect size demonstrated the sizes of difference in statistical analyses. Two sets of scores for the audio-oriented and visual-oriented groups on the pre-test and post-test were computed through Welch procedure. We applied Welch procedure because the number of audiooriented and visual-oriented learners in experimental group was not equal. According to Ruxton (2006), Welch's t-test is more effective even when the population variances are equal and sample sizes are balanced.

Qualitatively, we analysed the learners' responses to the interview questions. Precisely, the nature of learners' inner mental speech was detected when they had a visual and audio learning preference. The interactions were further scrutinized for the purpose of delving more deeply into the learners' inner speech differences.

\section{FINDINGS}

This section presents the findings of the study in accordance with the research questions. In this regard, first the research question is presented then the pertinent response.

\section{Research Question 1}

Does inner speech instruction have significant effects on L2 learners' reading comprehension?

Before responding to this question, we need to know whether the two groups' performance significantly differed at the pre-test level. The results of Independent samples t-test (table 3) shows an insignificant difference between the experimental and control group before inner speech instruction.

Table 3: Independent Samples T-test Results of the Experimental and Control Groups in the Pre-test

\begin{tabular}{llll}
\hline & & $\begin{array}{l}\text { Equal } \\
\text { Variances } \\
\text { assumed }\end{array}$ & $\begin{array}{l}\text { Equal } \\
\text { variances not } \\
\text { assumed }\end{array}$ \\
\hline $\begin{array}{l}\text { Levene's Test for } \\
\begin{array}{l}\text { Equality of } \\
\text { Variances }\end{array}\end{array}$ & $\mathrm{F}$ & .414 & \\
& Sig. & .523 & \\
\hline
\end{tabular}




\begin{tabular}{llll}
\hline t-test for Equality of & $\mathrm{t}$ & -1.215 & -1.215 \\
Means & $\mathrm{df}$ & 58 & 57.534 \\
& Sig.(2-tailed) & .229 & .229 \\
& Mean difference & -1.13333 & -1.13333 \\
& & \\
& Std. Error Difference & .93309 & .93309 \\
& & \\
& $95 \%$ Confidence interval & & \\
& Lower & -3.00111 & -3.00143 \\
& Upper & .73444 & .73477 \\
\hline
\end{tabular}

The results of the Levene's test for equality of variances showed a nonsignificant $p$-value $(p=.523)$ denoting that the assumption of equal variances was met, and therefore, the data in Table 3 could be interpreted. The results showed a statistically non-significant difference between the mean scores of the groups on the pre-test $(\mathrm{p}=$ $.229, \mathrm{t}=-1.21, \mathrm{df}=58)$ when equal variances were assumed. The magnitude of the difference showed -1.13 with $95 \%$ confidence interval ranging -3.00 to .73 which indicated a very small difference. Although the variances were shown to be equal, it was safer to report the last row of the table called Welch procedure because of the lack of enough power in testing the assumptions in SPSS. The results of the Welch procedure also showed a non-significant difference $(\mathrm{p}=.229, \mathrm{t}=-1.21, \mathrm{df}=57.53)$. The mean difference also showed a very small difference (mean difference $=-1.13,95 \% \mathrm{CI}=-3.00$ to .73) which confirmed the same results as the first line and that the two groups were similar at the beginning of the study.

Comparison between two groups' performance at the post-test level is presented in Table 4. The results of the Welch procedure showed a significant difference between the mean scores obtained from the two groups $(\mathrm{p}=.001, \mathrm{t}=3.73, \mathrm{df}=42.12)$. The magnitude of the difference in means was 2.43 with $95 \%$ confidence interval ranging between 1.11 to 3.74 and showed a large difference (Cohens' $d=.96$ ) suggesting that the experimental group outperformed the control group after receiving the treatment (see Table 4). According to the proposed norm for effect size by Cohen (1988), the calculated effect size demonstrated a large difference between the two groups' performance. This difference confirmed the effectiveness of inner speech instruction on the experimental group's performance.

Table 4: Independent Samples T-test Results of the Experimental and Control Groups in the Post-test

\begin{tabular}{lcll}
\hline & & $\begin{array}{l}\text { Post-test } \\
\text { Equal } \\
\text { Variances } \\
\text { assumed }\end{array}$ & $\begin{array}{l}\text { Post-test } \\
\text { Equal } \\
\text { variances not } \\
\text { assumed }\end{array}$ \\
\hline $\begin{array}{l}\text { Levene's Test for } \\
\begin{array}{l}\text { Equality of } \\
\text { Variances }\end{array}\end{array}$ & F & 10.065 & \\
\hline
\end{tabular}




\begin{tabular}{llll}
\hline t-test for Equality of & $\mathrm{t}$ & 3.730 & 3.730 \\
Means & $\mathrm{df}$ & 58 & 42.126 \\
& Sig.(2-tailed) & .000 & .001 \\
& & \\
& Mean difference & 2.43333 & 2.43333 \\
& & \\
& Std. Error Difference & .65229 & .65229 \\
& & \\
& $95 \%$ Confidence interval & & \\
& Lower & 1.12764 & 1.11708 \\
& Upper & 3.73903 & 3.74959 \\
\hline
\end{tabular}

The experimental group's performance in the pre-test and the post-test was also compared to reveal whether their performance improved after the inner speech instruction sessions. Table 5 below displays a meaningful difference $(t=-6.987)$ between the experimental group's performance in the pre and post-test performance, which confirms the effectiveness of instruction stage on experimental group members.

Table 5: Paired-samples T-test Results of the Experimental Group

\begin{tabular}{|c|c|c|c|c|c|c|c|c|}
\hline & \multicolumn{5}{|c|}{ Paired Differences } & \multirow{3}{*}{\multicolumn{2}{|c|}{$\mathrm{t} \quad \mathrm{df}$}} & \multirow{3}{*}{$\begin{array}{l}\text { Sig. } \\
(2- \\
\text { tailed) } \\
\end{array}$} \\
\hline & \multirow[t]{2}{*}{ Mean } & \multirow[t]{2}{*}{$\begin{array}{l}\text { Std. } \\
\text { Dev. }\end{array}$} & \multirow[t]{2}{*}{$\begin{array}{l}\text { Std. } \\
\text { Error } \\
\text { Mean }\end{array}$} & \multicolumn{2}{|c|}{$\begin{array}{l}95 \% \text { Confidence } \\
\text { Interval of the } \\
\text { Difference }\end{array}$} & & & \\
\hline & & & & Lower & Upper & & & \\
\hline $\begin{array}{l}\text { Exper. } \\
\text { Pre-test - } \\
\text { Post-test }\end{array}$ & -4.33 & $\begin{array}{l}3.39 \\
7\end{array}$ & .6202 & -5.601 & -3.064 & -6.98 & 29 & .000 \\
\hline
\end{tabular}

Note: Exper: Experimental; Std. Dev: Standard deviation

\section{Research Question 2}

Does inner speech instruction lead to significant differences between visual and auditory learners in reading comprehension tasks?

To answer this question, the results of the Levene's test showed that the two groups were equal in terms of homogeneity of variances. Accordingly, the analysis indicates a non-significant $\mathrm{p}$-value $(\mathrm{p}=.362, \mathrm{t}=.92, \mathrm{df}=28)$ when equal variances were assumed in the pre-test. The mean difference was also 1.30 which showed a very small difference $(95 \% \mathrm{CI}=-1.58$ to 4.19$)$. The results of the Welch procedure also showed a non-significant difference $(\mathrm{p}=.391, \mathrm{t}=.87, \mathrm{df}=19.30)$ and a very small difference (mean difference $=1.30,95 \% \mathrm{CI}=-1.80$ to 4.41 ) and confirmed the results when equal variances were assumed (see Table 6). It can, therefore, be seen that the two groups were not different at the outset of the study. 
Table 6: Independent Samples T-test Results of the Auditory and Visual Groups in the

\begin{tabular}{llll}
\multicolumn{1}{c}{ Pre-test } & & $\begin{array}{l}\text { Pre-test } \\
\text { Equal } \\
\text { Variances } \\
\text { assumed }\end{array}$ & $\begin{array}{l}\text { Pre-test } \\
\text { Equal } \\
\text { variances } \\
\text { not assumed }\end{array}$ \\
\hline $\begin{array}{l}\text { Levene's Test for } \\
\begin{array}{l}\text { Equality of } \\
\text { Variances }\end{array}\end{array}$ & $\mathrm{F}$ & 1.057 & \\
\hline t-test for Equality of & $\mathrm{Sig}$. & .313 & \\
Means & $\mathrm{df}$ & .926 & .877 \\
& Sig.(2-tailed) & 28 & 19.307 \\
& Mean difference & 1.362 & .391 \\
& Std. Error Difference & 1.40952 & 1.48913 \\
& 95\% Confidence interval & & \\
& Lower & -1.58171 & -1.80787 \\
& Upper & 4.19283 & 4.41898 \\
\hline
\end{tabular}

On the other hand, results of independent samples t-test showed a nonsignificant $\mathrm{p}$-value $(\mathrm{p}=.545)$ suggesting that the assumption of equal variances was met. Following that, examining the audio-oriented and visual-oriented learners at the post-test level showed a non-significant $\mathrm{p}$-value $(\mathrm{p}=.578, \mathrm{t}=.563, \mathrm{df}=28)$ suggesting that the two groups of participants were not statistically different (see Table 7). The mean score difference was .33 with $95 \%$ confidence interval ranging between -.87 to 1.54 which showed a negligible difference (Cohen's $\mathrm{d}=.20$ ). The Welch procedure also showed similar results, that is, non-significant difference $(\mathrm{p}=.595, \mathrm{t}=.54, \mathrm{df}=20.41)$. The mean difference also showed a negligible difference (Mean difference $=.33,95 \%$ $\mathrm{CI}=-.95$ to 1.61 ) (see Table 7). The results, therefore, suggested that both groups performed equally well on the post-test and after receiving the instruction.

Table 7: Independent Samples T-test Results of the Auditory and Visual Groups in the Post-test

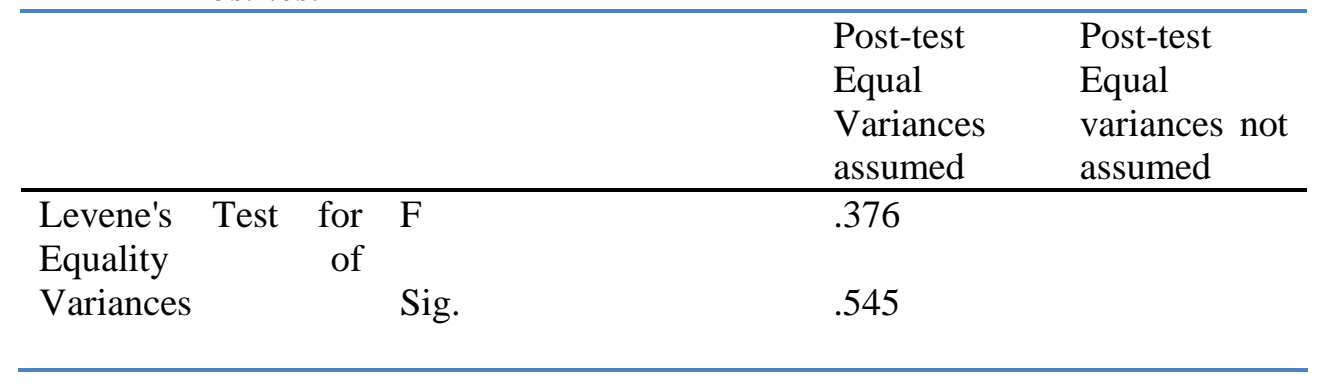




\begin{tabular}{llll}
\hline t-test for Equality of & $\mathrm{t}$ & .563 & .541 \\
Means & $\mathrm{df}$ & 28 & 20.412 \\
& Sig.(2-tailed) & .578 & .595 \\
& Mean difference & .3333 & .3333 \\
& & \\
& Std. Error Difference & .59205 & .61666 \\
& & \\
& & \\
& 95\% Confidence interval & & \\
& Lower & -.87944 & -.95134 \\
& Upper & 1.54610 & 1.61801 \\
\hline
\end{tabular}

\section{Research Question 3}

Does inner speech instruction lead to significant changes in visual learners in reading comprehension tasks?

The results of the table of paired-samples t-test showed that the difference between the pre-test and post-test scores of the visual group was statistically different. The magnitude of the increase was -4.91 with $95 \%$ confidence interval ranging from 6.91 to -2.91 . Cohen's d statistics also showed a large difference (Cohen's $d=-1.47$ ) indicating that the learners with visual learning style benefitted the instruction (see Table 8).

Table 8: Paired-samples T-test Results of the Visual Group

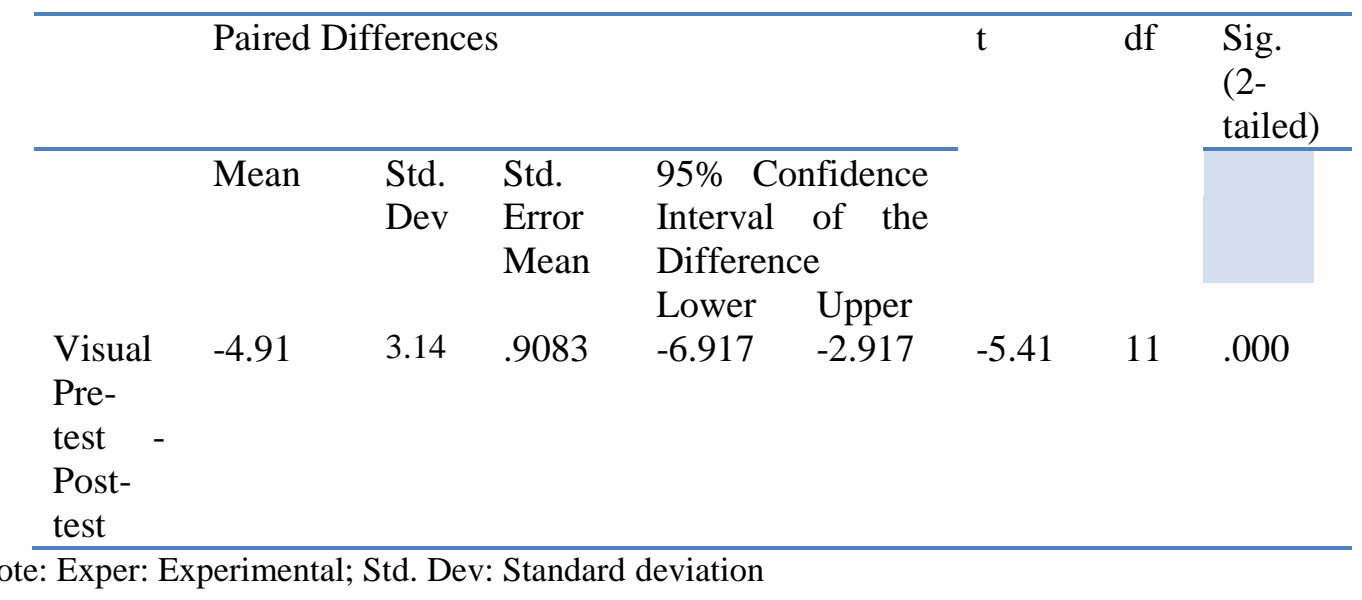

\section{Research Question 4}

Does inner speech instruction lead to significant changes in auditory learners in reading comprehension tasks?

The fourth research question is to determine whether auditory styles had a different performance between their pre-test and post- test or not. The table of descriptive statistics indicated that the learners with auditory learning style obtained a higher mean score on the post-test $(\mathrm{M}=24.60, \mathrm{SD}=1.45)$ than on the pre-test $(\mathrm{M}=$ 
$20.72, \mathrm{SD}=3.33$ ) indicating that the instruction was helpful to them and their reading comprehension ability (see Table 9.).

Table 9: Descriptive Results for the Reading Comprehension Scores of the Auditory

\begin{tabular}{llllll}
\hline \multicolumn{1}{c}{ Group } & & Mean & N & $\begin{array}{l}\text { Std. } \\
\text { Deviation }\end{array}$ & $\begin{array}{l}\text { Std. Error } \\
\text { Mean }\end{array}$ \\
\hline Auditory & Pre-test & 20.722 & 18 & 3.339 & .787 \\
\hline & $\begin{array}{l}\text { Post- } \\
\text { test }\end{array}$ & 24.667 & 18 & 1.455 & .343 \\
\hline
\end{tabular}

\section{Research Question 5}

What is the nature of inner speech in auditory and visual style learners and their perceptions toward inner speech?

This qualitative research question addressed the nature of inner speech in both styles (Auditory and visual) and their perceptions about inner speech instruction. To answer this question, an open-ended questionnaire was given to the participants. For brevity, some selective responses to the questions are shown here:

Q1: Did you "hear" the sounds of English in your mind? Did they relate to your class? Visual students

1. Yes, I did and hearing the sounds in English help me to better understand, analyzing and comprehending the text. I hear the sounds from class.

2. Yes, it is related to my class.

3. Yes, I did and it was related to the class.

Auditory Students

1. Yes, I did. I heard the sounds of English in my mind.

2. Yes I did, yes it was.

3. Sometimes, it can be helpful especially when you're practicing another language.

As a result, it was inferred that both styles were hearing some voices during reading which was related to their inner speech and class experiences. Moreover, they were using it for better understanding, analyzing texts and practicing for learning a new language.

Q2: Did you visualize the words in your mind?

Visual students

1. Yes, I did. It helped me make better sentences for understanding each paragraph.

2. Yes, it helps me memorize the words.

3. Yes, of course, I did. For example it was about its spelling, and create my sentences in order to memorize the spelling and my first language help me for example for memorizing the word "jealous" I imagine someone with the sentence "jelez o velezkardan" and then it helps me to remember the word jealous when I am in a challenging situation. 


\section{Auditory Students}

1. Yes, I visualized words in my mind for example some words such as garage, bicycle etc.

2. Not so much.

3. For sure, in my opinion, visualizing is one of the useful ways to understand.

The analysis of second question showed that visual learners were using visualization for memorizing words and they were relating it to their first language just like the auditory group.

Q3: From what perspective do you see the images?

Visual students:

1. Seeing image helps me analyze the text better.

2. It helps me have a better understanding and

3. from the perspective that you can feel the things better.

Auditory Students:

1. I see them for learning a specific lesson.

2. I do not use it much.

3. I sometimes draw some images for myself.

As a result, this question shows that visual learners benefited more from seeing images during their inner speech experience and auditory learners didn't use it.

Q4: Which of the first two questions was most important when you were mentally rehearsed?

Visual students:

1. In my opinion, all of the elements that were mentioned are important but visualizing the words in my mind was most central to my awareness.

2. Visualizing was most central

3. Visualizing?

Auditory Students:

1. Seeing images

2. Hearing voices

3. Visualizing

It is understood that all the three visual learners used visualizing more during their inner speech experience but the auditory learners did not do so.

Q5: Do you think the inner speech instruction was helpful? Explain how it was?

Visual students:

1. All of the abovementioned factors are helpful each of them effective in a different way. It helps the learner to have a good comprehension and I think comprehension is a main element for learning another language. 
2. At first students did not know about it at all but step by step it became clear for them and understand it when they were involved in learning process.

3. It is because it was a kind of repetition or a way of becoming ready for giving the main ideas of the readings.

\section{Auditory Students:}

1. Yes, inner speech helped students to understand the texts, and helped them to remember things in mind.

2. Yes, it helped understand the text faster, and

3. It can improve their comprehending the text in the learning process.

It was revealed that both of the styles benefited from inner speech instruction in different ways. For visual learners it was beneficial for comprehending the text better, repetition, and making them ready for giving the main ideas. On the other hand, for auditory learners it helped them to understand and remember the material in their mind, understand faster and improve comprehension.

\section{DISCUSSION AND CONCLUSION}

Regarding the first research question about the effect of inner speech instruction on reading ability, the results of the study showed a significant difference, suggesting that performance of the participants on reading comprehension ability improved. In addition, there was no significant difference between the control and experimental group in the pre-test but by comparing the post-test results of the two groups, it revealed that the experimental group out-performed the control group after receiving the treatment. The results of this section are not consistent with the work of Tahmasebi and Yamini (2011) who tested the role of private speech in reading comprehension and oral production of EFL students.

The second research question asked about the difference in the reading improvement of the participants with visual and auditory styles after receiving the inner speech instruction. The results showed that the participants with visual learning style improved to a large extent from the pre-test to post-test. In addition, this result was identical for the auditory style. The results of the study suggest that inner speech instruction raises EFL learners' awareness of their inner dialogue and in particular improves the reading comprehension performance in an EFL/ESL context.

As for the third and fourth research question which investigated a significant difference between auditory and visual learners' reading comprehension performance after receiving the treatment, the results of pre-test showed that the two groups had similar performance, and also from independent samples t-test it was revealed that both groups performed equally well on the post-test.

Finally, qualitative data revealed that both visual and auditory styles of learning use inner speech for comprehending better, analysing texts better, and practicing. Moreover, visual learners used visualization for memorizing words more than the auditory learners and they were both hearing some voices. In addition, both styles benefited from inner speech instruction in a different way such as comprehending the 
text, repetition and focusing better before giving the main idea. The results of this part are consistent with the work of Hardyck and Petrinovich (1970) who believed that the inner speech consists of auditory images. Sokolov (1972) contended that the use of graphic image during inner speech suggests that similar to overt speech inner speech has a strong extra linguistic component and the visual image shaped during second language inner speech is the non-linguistic, affective, and integral component of intrapersonal communication (cited in Lantolf \& Appel, 1994). In addition, both styles benefited from inner speech instruction in a different way such as comprehending the text, repetition and focusing better before giving the main idea.

To sum up, the present study aimed to investigate the effectiveness of inner speech instruction on EFL learners' reading comprehension. Regardless of their proficiency level in English, the participants who received instruction in inner speech improved their performances, while participants who did not receive the instruction showed no significant change in their performances from pre-test to the post-test. Moreover, visual and auditory styles benefited from the instruction. These findings suggest that the use of inner speech results in better comprehension of reading texts. The results indicated that visual and auditory learners benefited equally from inner speech. It was also found that inner speech could bring new insights into the processes involved in the reading comprehension in L2 contexts. Lastly, the results of interview revealed that visual learners preferred more visualizing materials, but auditory learners had more voice hearing experiences during their inner speech experience.

On the implication side, it is assumed that English teachers and mediators could assist learners to internalize concepts through inner speech instruction. Applying inner mental self-speech instruction in a social context of classroom leads learners to move from inter-psychological to intra-psychological world in order to modify their current developed ability to higher cognitive functioning.

\section{REFERENCES}

Abadikhah, S., \& Khorshidi, A. (2013).An investigation of the private speech in the collaborative interaction of Iranian adult EFL Learners. The Southeast Asian Journal of English Language Studies, 19(3), 71 - 85.

Abdollahi, H., \& Tahriri, A. (2012). The relationship between learning styles and vocabulary recall of EFL learners. Iranian EFL Journal. 8(6). 11-27.

Aliakbari M. \& Abol-Nejadian, R. (2013). Trait emotional intelligence and learning styles: the case of Iranian English for Academic Purposes Learners. Educational Psychology. 35(7), 779-793.

Best, J. W. (2006). Research in education (10th ed.). Boston: Pearson.

Buckwalter, P. (2001). Repair sequences in Spanish L2 dyadic discourse: A descriptive study. The Modern Language Journal. 85(3), 380-397.

Claxton, C., \& Murrel, P. (1987). Learning styles: implications for improving education practices. ASHE-ERIC Higher education.1-16.

Cohen, J. (1988). Statistical power analysis for the behavioral sciences $\left(2^{\text {nd }}\right.$ ed.). Hillsday, N. J., Erlbaum. 
DiCamilla, F.J., \& Anton, M. (2004). Private speech: A study of language for thought in the collaborative interaction of language learners. International Journal of Applied Linguistics, 14(1), 36-69.

Dorneyei, Z. (2005). The psychology of the language learner: Individual differences in second language acquisition. Mahwah, NJ: Lawrence Erlbaum Associates.

Frawley, W. \& Lantolf, J. P. (1985). L2 discourse: A Vygotskyan perspective. Applied Linguistics, 6(1), 19-44.

Frawley, W. (1997).Vygotsky and cognitive science. Language and the unification of the social and computational mind. Cambridge, MA: Harvard University Press.

Grabe, W. (2009). Reading in a second language: Moving from theory to practice. New York. United Sates of America. Cambridge University Press.

Guerrero, M. C. M. (2005). Inner Speech—L2: Thinking words in a second language. New York: Springer.

Keefe, J., \& Ferrell, B. (1990). Developing a defensible learning style paradigm. Educational leadership, 48(2), 57-61.

Keefe, J. W. (1979). Learning style: An overview. In J.W. Keefe (Ed.), Student Learning Styles: Diagnosing And Prescribing Programs (pp.1-17). Reston, VA: National Association of Secondary School Principals.

Lantolf, J. P., \& Appel, G. (1994). Vygotskian approaches to second language research. Norwood, N. J: Ablex.

Mcchlery, S. \& Visser, S. (2009). A comparative analysis of the learning styles of accounting students in the United Kingdom and South Africa. Research in Post-Compulsory Education. 14(3), 299-315.

McCafferty, S.G. (1992). The use of private speech by adult second language learners: A crosscultural study. The Modern Language journal, 76(2), 179-189.

Oxford, R. (1995). Gender differences in learning styles: What do they mean? In J. M .Reid (Ed.), Learning Styles in the ESL/EFL classroom (pp.34-40). Boston: Heinle and Heinle.

Oxford, R. (2003). Language learning styles and strategies: An overview. Oxford: Oxford University Press.

Platt, E. \& Brooks, F.B. (1994). The acquisition-rich environment revisited. The Modern Language Journal. 78(4), 497-511.

Putinseva, P. (2006). The importance of learning styles in ESL/EFL. The Internet TESL Journal. 12(3).

Reid, J.M. (1995). Learning styles in the ESL classroom. Boston: Heinleand Heinle.

Ruxton, G. D. (2006). The unequal variance t-test is an underused alternative to student's t-test and the Mann-Whitney U test. Behavioral Ecology. 17, 688-690.

Sadler-Smith, E. (2010). 'Learning Style': frameworks and instruments. Educational Psychology. 17(1), 51-63.

Saville-Troike, M. (1988). Private speech: Evidence for second language learning -strategies during the silent period. Journal of Child Language. 15(3), 567-90.

Tahmasebi, S. \& Yamini, M. (2011). Linking task-based language teaching and sociocultural theory: Private speech and scaffolding in reading comprehension. Advances in Language and Literacy Studies. 2(1), 41-55.

Upton, T. A. \& Lee-Thompson, L. (2001). The role of the first language in second language reading. Studies in Second Language Acquisition, 23(4), 469-495.

Villamil, O. \& DeGuerrero, M. (1996). Peer revision in the L2 classroom: Social-cognitive activities, mediating strategies, and aspects of social behavior. Journal of Second Language Writing. 5(1), 51-75.

Vygotsky, L. S. (1986). Thought and language. Cambridge, MA: The MIT press.

Williams, B., Brown, T. \& Etherington, J. (2012). Learning styles Preferences of Undergraduate Social Work Students. Social Work Education, 32, 972-990. 
Winsler, A.; Diaz, R. \& Montero, I. (1997). The role of private speech in the transition from collaborative to independent task performance in young children. Early Childhood Research Quarterly 12(1), 59-79.

Winsler, A.; L. Manfra \& Diaz, R. (2007). Should I let them talk: Private speech and task performance among preschool children with and without behavior problems. Early Childhood Research Quarterly. 22, 215-231.

\begin{abstract}
AUTHORS
Karim Shabani holds a PhD in TEFL from the University of Tehran and is currently the assistant professor at Allameh Mohaddes Nouri University. He has presented a number of papers in international conferences like ICELT2009 (UPM), TELLSI6, TELLSI7, TELLSI9, TELLSI10, ILI conference, ICELET2012 (University of Tehran), etc. His current areas of interest are Vygotsky's Socio-cultural Theory, (dynamic) testing/assessment and L2 development.
\end{abstract}

Ghazaleh Khasrei is an MA holder of TEFL from Allameh Mohaddes Nouri University. Her research interests are on inner speech and sociocultural theory.

Iman Bakhoda is an MA holder of TEFL from Allameh Mohaddes Nouri University. $\mathrm{He}$ is interested in doing research on Vygotsky's sociocultural theory and dynamic assessment. 